Review began 02/01/2022 Review ended 02/05/2022 Published 02/14/2022

\section{() Copyright 2022}

Ibrahim et al. This is an open access article distributed under the terms of the Creative Commons Attribution License CC-BY 4.0., which permits unrestricted use, distribution, and reproduction in any medium, provided the original author and source are credited.

\title{
Five Ectopic Teeth in the Maxillary Sinus: A Rare Cause of Chronic Sinusitis
}

\author{
Mohamad Ali Ibrahim ${ }^{1}$, Said EL Orra ${ }^{2}$, Nagham Ramadan ${ }^{1}$, Ahmad Lakis ${ }^{3}$, Mohammed Dabbous ${ }^{4}$ \\ 1. Medicine, Faculty of Medicine, Saint Joseph University, Beirut, LBN 2. Internal Medicine, Beirut Arab University, \\ Beirut, LBN 3. Radiology, Medical Care Laboratories and Radiology Center, Chtoura, LBN 4. Internal Medicine, \\ Lebanese University Faculty of Medicine, Beirut, LBN
}

Corresponding author: Mohammed Dabbous,dr.dabbous@hotmail.com

\begin{abstract}
Around $10-20 \%$ of sinusitis have a dental etiology. Odontogenic sinusitis is generally caused by periodontitis, peri-implantitis, periapical pathology, or oroantral communication. Ectopic teeth are a rare cause of chronic odontogenic sinusitis. We present a rare case of chronic sinusitis caused by five ectopic teeth.

A 39-year-old-female patient presented to our clinic with complaints of facial pain over the left cheek, ipsilateral nasal obstruction, ipsilateral rhinorrhea, and coughing over the last five years. Physical examination revealed a febrile patient. There was an ipsilateral purulent nasal discharge of yellow color. Inspection of the oral cavity revealed the absence of the following maxillary teeth: left first and second premolars, in addition to the left first, second, and third molars. There was also tenderness upon palpation of the left maxillary sinus. Computed tomography (CT) scan of the maxillary sinus revealed hyperdense structures in the left maxillary sinus surrounded by soft tissue, representing the missing premolar and molar teeth. The patient was treated with amoxicillin-clavulanate and corticosteroid, which partially relieved her symptoms.
\end{abstract}

Our case presents an unusual case of chronic sinusitis that was found to be a consequence of five ectopic teeth in the maxillary sinus. A careful physical examination and an appropriate imaging modality are indispensable for the diagnosis of such a rare phenomenon.

Categories: Internal Medicine, Otolaryngology, Dentistry

Keywords: case report, supernumerary teeth, sinusitis, maxillary sinus, ectopic teeth

\section{Introduction}

Eruption of teeth is the process by which teeth migrate from the loci of their formation in the mandible and maxilla to their functional place in the oral cavity [1]. The process of teeth development starts early at the fifth week during the embryonic period [2]. Tooth maturation was found to be strongly correlated to tooth eruption timing [3]. In addition, a number of growth factors, genes, and extracellular molecules, along with the interaction between the mesenchyme and ectoderm, represent important factors for proper tooth development [4].

Teeth can sometimes reside in unusual locations; this is known as ectopic teeth eruption. The mandibular condyle, coronoid process, orbit, palate, nasal cavity, and the maxillary sinus were the predilection sites for ectopic teeth eruption as reported in the literature [5-10]. Moreover, most of the reported cases in the literature involved only one ectopic tooth, and cases reporting more than two ectopic teeth were rare [11].

To our knowledge, this is the first case of chronic sinusitis caused by five ectopic teeth in the maxillary sinus.

\section{Case Presentation}

A 39-year-old woman presented to our clinic with complaints of facial pain over the left cheek, ipsilateral nasal obstruction, ipsilateral rhinorrhea, and coughing over the last five years. Due to financial reasons, the patient did not seek medical attention and decided to manage her symptoms through antibiotics, without showing any sign of improvement. The patient denied a history of trauma. She had no relevant family history or had any surgical or dental procedures in the past.

Physical examination revealed a febrile patient $\left(38.5^{\circ} \mathrm{C}\right)$. There was an ipsilateral purulent nasal discharge of yellow color. Inspection of the oral cavity revealed the absence of the following maxillary teeth: left first and second premolars, in addition to the left first, second, and third molars. There was also tenderness upon palpation of the left maxillary sinus. 


\section{Cureus}

Due to the chronicity of her symptoms and the unexplained absence of the aforementioned teeth, a CT scan of the maxillary sinus was performed, which revealed hyperdense structures surrounded by soft tissue in the left maxillary sinus, which most probably represented the missing left molar and premolar teeth (Figures 1 , 2).

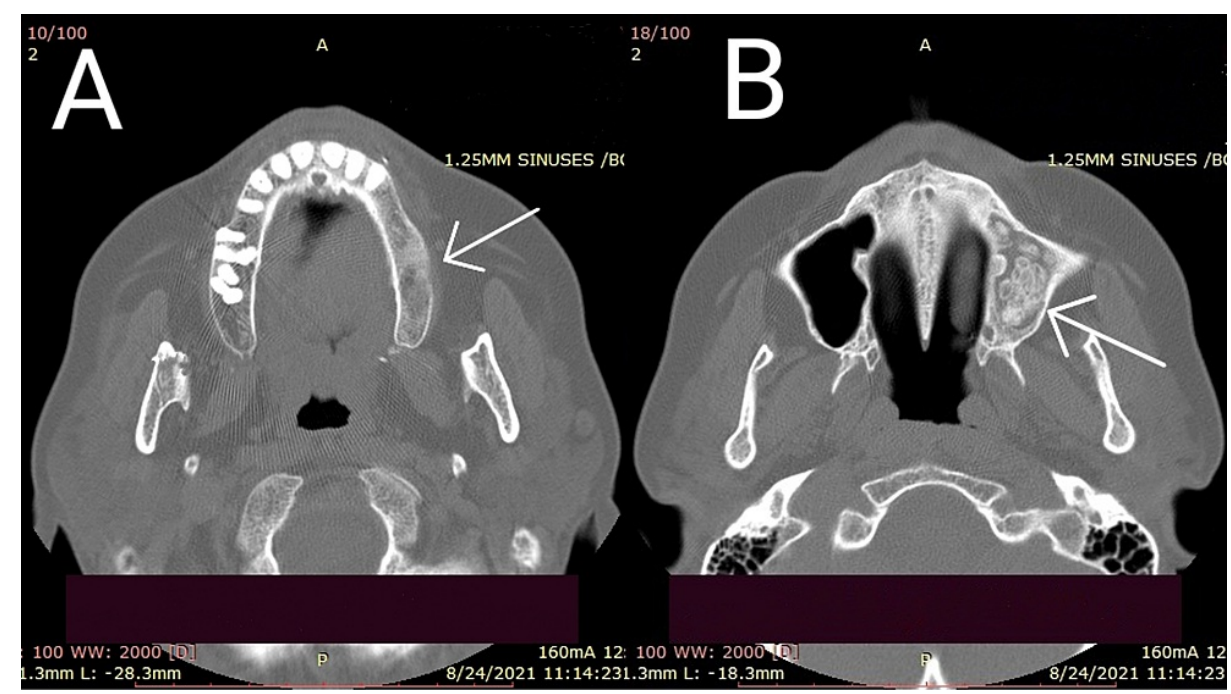

\section{FIGURE 1: CT scan of the maxilla}

(A) Axial view showing the absence of the molar and premolar teeth on the left side compared to the right side, which showed normal growth of teeth. (B) Axial view showing hyperdense structures in the left maxillary sinus surrounded by soft tissue, representing the missing left premolar and molar teeth.

$\mathrm{CT}$, computed tomography

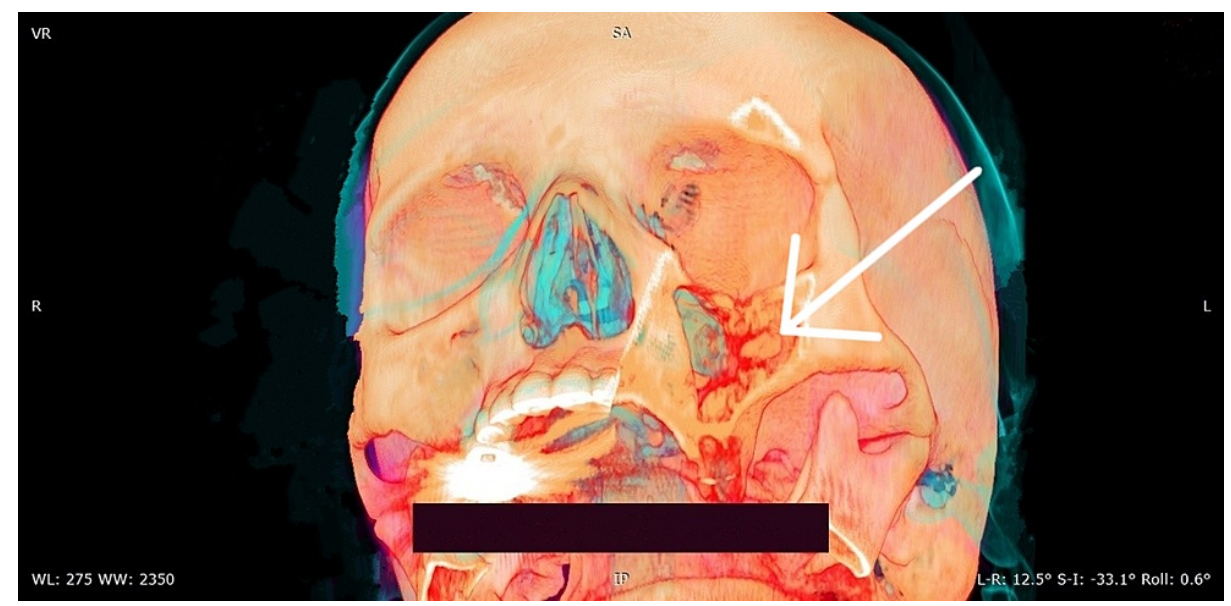

FIGURE 2: Reconstructed 3D CT image with supralateral angulation showing the undescended teeth in the left maxillary sinus

3D CT, three-dimensional computed tomography

Due to financial reasons, tooth extraction surgery could not be performed, and the patient was instead treated with amoxicillin/clavulanic acid $(875 \mathrm{mg} / 125 \mathrm{mg}$ ) one tablet every 12 hours for 14 days, paracetamol 1g 1 tablet every six hours, intranasal corticosteroid, and saline irrigation of the nasal cavities. Follow-up every two weeks for a period of four months revealed minimal relief of the ipsilateral facial pain, with a complete resolution of fever, ipsilateral rhinorrhea, nasal obstruction, and cough.

\section{Discussion}

Ectopic teeth and supernumerary teeth account for $1 \%$ of the total population [12]. The etiology of ectopic tooth remains unclear. However, several factors may be implicated in its development, such as genetic 
factors, anomalies, trauma, and infection [13]. In our case, the patient did not have a history of trauma, crowded teeth, or any other causative factor, and thus the reason behind the ectopic teeth in our case remained unknown.

Around 52 cases of ectopic teeth in the maxillary sinus have been reported. According to multiple case reports, ectopic teeth involved the right and left maxillary sinuses equally. In addition, the third molar was found to be the most common ectopic tooth in the maxillary sinus [11].

Patients with ectopic teeth in the maxillary sinus are mostly asymptomatic, and the condition is incidentally diagnosed during an investigation for another purpose [14]. However, most reported cases described the presence of symptoms such as facial numbness, purulent nasal discharge, rhinorrhea, headache, and fever [11]. In our case, the patient presented with fever, facial pain, ipsilateral rhinorrhea, ipsilateral nasal obstruction, and coughing over five years, for which she did not seek medical attention due to the lack of financial means.

Since teeth are radiopaque, plain radiographs, panoramic radiographs, and Water graphy have the capability to detect the ectopic ones. Cone-beam computed tomography (CBCT) and CT scan are also accepted as imaging modalities for diagnosing ectopic teeth [15]. However, CT (CBCT or CT scan) remains the most accurate imaging modality, with an advantage of CBCT due to its lower dose when compared to the CT scan [16]. Due to the unavailability of CBCT in the institution, the method used was CT scan, which revealed hyperdense structures at the level of the left maxillary sinus.

A clinical follow-up is recommended when the patient is asymptomatic [11]. In symptomatic patients, the recommended treatment is surgical resection of the ectopic teeth. The Caldwell-Luc approach, with or without transoral endoscopy, and nasal endoscopy are two accepted surgical methods [17]. Surgical intervention was an indication in our case, but it was not performed due to financial reasons. However, the patient showed some improvement in her symptoms with the medical therapy.

\section{Conclusions}

Ectopic tooth is an unusual cause of chronic sinusitis. As described in our case, the patient had chronic sinusitis over the last five years, which was unexpectedly discovered to be caused by ectopic teeth. Hence, physicians and dentists are encouraged to consider the possibility of the presence of ectopic teeth in the maxillary sinus in patients with chronic sinusitis by focusing on a careful physical examination and utilizing a suitable imaging modality.

\section{Additional Information \\ Disclosures}

Human subjects: Consent was obtained or waived by all participants in this study. Conflicts of interest: In compliance with the ICMJE uniform disclosure form, all authors declare the following: Payment/services info: All authors have declared that no financial support was received from any organization for the submitted work. Financial relationships: All authors have declared that they have no financial relationships at present or within the previous three years with any organizations that might have an interest in the submitted work. Other relationships: All authors have declared that there are no other relationships or activities that could appear to have influenced the submitted work.

\section{References}

1. Yaseen SM, Naik S, Uloopi KS: Ectopic eruption - a review and case report . Contemp Clin Dent. 2011, 2:3-7. 10.4103/0976-237X.79289

2. Hovorakova M, Lesot H, Peterka M, Peterkova R: Early development of the human dentition revisited . J Anat. 2018, 233:135-45. 10.1111/joa.12825

3. Demirjian A, Goldstein H, Tanner JM: A new system of dental age assessment . Hum Biol. 1973, 45:211-27.

4. Santosh $\mathrm{AB}$, Jones TJ: The epithelial-mesenchymal interactions: insights into physiological and pathological aspects of oral tissues. Oncol Rev. 2014, 8:239. 10.4081/oncol.2014.239

5. Srivastava RP, Singh G: An unusual impacted inverted molar in mandibular condyle with preauricular sinus (a case report). J Indian Dent Assoc. 1982, 54:67-9.

6. Wong YK, Liew JC, Tsui SH, Cheng JC: Ectopic molar near the coronoid process: case report . Quintessence Int. 2007, 38:597-600.

7. Garde JB, Kulkarni AU, Dadhe DP: Ectopic tooth in the orbital floor: an unusual case of dentigerous cyst . BMJ Case Rep. 2012, 2012:bcr1120115266. 10.1136/bcr.11.2011.5266

8. Golovcencu L, Costan VV: [Canine teeth impacted in the palate--case report] . Rev Med Chir Soc Med Nat Iasi. 2011, 115:1267-70.

9. Pracy JP, Williams HO, Montgomery PQ: Nasal teeth. J Laryngol Otol. 1992, 106:366-7. $10.1017 / \mathrm{s} 0022215100119516$

10. Srinivasa Prasad T, Sujatha G, Niazi TM, Rajesh P: Dentigerous cyst associated with an ectopic third molar in the maxillary sinus: a rare entity. Indian J Dent Res. 2007, 18:141-3. 10.4103/0970-9290.33793

11. Lombroni LG, Farronato G, Santamaria G, Lombroni DM, Gatti P, Capelli M: Ectopic teeth in the maxillary sinus: a case report and literature review. Indian J Dent Res. 2018, 29:667-71. 10.4103/ijdr.IJDR_347 17 


\section{Cureus}

12. Moreano EH, Zich DK, Goree JC, Graham SM: Nasal tooth. Am J Otolaryngol. 1998, 19:124-6. 10.1016/s01960709(98)90108-9

13. Baykul T, Doğru H, Yasan H, Cina Aksoy M: Clinical impact of ectopic teeth in the maxillary sinus . Auris Nasus Larynx. 2006, 33:277-81. 10.1016/j.anl.2006.01.004

14. Topal Ö, Dayısoylu EH: Ectopic tooth in the maxillary sinus . Turk Arch Otorhinolaryngol. 2017, 55:151-2. 10.5152/tao.2017.2308

15. Yang P, Liang H, Zou B, Liu J, Yuan D, Meng Z, Xu K: Ectopic tooth in maxillary sinus compressing the nasolacrimal canal: A case report. Medicine (Baltimore). 2021, 100:e25514. 10.1097/MD.0000000000025514

16. Ngoc VT, Anh LQ, Duc NM, Dinh TC, Dinh TC: Cone beam computed tomography application in finding ectopic tooth: a systemic analysis and a case report. Open Access Maced J Med Sci. 2019, 7:4333-6. 10.3889/oamjms.2019.386

17. Courtot R, Devoize L, Louvrier A, et al.: Surgical approach of ectopic maxillary third molar avulsion: systematic review and meta-analysis. J Stomatol Oral Maxillofac Surg. 2021, 122:77-82.

10.1016/j.jormas.2020.06.015 